\title{
INTELLIGENT SERVICE PUSH METHOD BASED ON ACTIVE GEOGRAPHIC PERCEPTION
}

\author{
Jianwu Jiang ${ }^{1}$, Jingwen $\mathrm{Li}^{1,}{ }^{1,}$,Jingshan $\mathrm{Wei}^{1}$, Zhipeng $\mathrm{Su}^{1}$ \\ ${ }^{1}$ Guilin University of Technology, Guilin, China - (fengbuxi, Lijw)@glut.edu.cn, (378278211,690505391)@qq.com
}

KEY WORDS: Active perception Geographic, Feature model, User motivation, Smart service, Data mining

\begin{abstract}
:
In view of the lack of consideration of user behavior motives in traditional personalized precision service systems, the accuracy of service content is not high.In order to solve this problem, research on personalized accurate service push method based on active geographic perception. By constructing a geographic feature information model, get the characteristics of the user's destination in real time, and then infer the user's behavioral motivation. Focusing on active geographic awareness technology and personalized precision service methods, the concept, principle, process and key technologies of active geographic sensing are studied, determined the main research content of active geographic perception and the relationship. Then analyze and discuss the construction method of active geographic awareness architecture, developed a geographic feature content system and studied its extraction and weight calculation methods. By the way, according to the characteristics of active geo-sensing, an active awareness API conforming to high efficiency and real-time is designed. Then explored the personalized accurate service push method based on active geographic perception,designed three processes of geographic awareness, service retrieval and service push, a service retrieval and delivery method is proposed. Finally, a personalized precise service system based on active geographical perception is designed. By adding geographic features to the personalized precision service, it can make up for the lack of service personalization and lack of precision caused by ignoring user motivation, which provides a new idea for more accurate and personalized service push.
\end{abstract}

\section{INTRODUCTION}

Under the multiple influences of big data, cloud computing, mobile Internet and in-depth learning,Enhancing the wisdom of service, increasing the individualization of service content and improving the accuracy of service have become three main problems in service industry research ${ }^{[1]}$. Around the above three issues,many scholars have carried out in-depth research and put forward a large number of theoretical and technical support.However, most of the current research only considers the user and project dimensions, which leads to the generalization and solidification of the recommended algorithm. The reason for this problem is that the user's activities are not only affected by personal preferences, but also related to the user's situation. Situation reflects the user's behavioral motivation,the unified intelligent service can be universally applied, but because of the less motivation for considering user behavior, when the user has a subjective purpose, the accuracy of the service will be deviated. In order to solve this problem, this paper studies the user motivation inference method based on active geographic perception, which narrows the user's preference to the time level, and then improves the accuracy of intelligent service.

\section{ACTIVE GEOGRAPHIC PERCEPTION ARCHITECTURE}

\subsection{The Meaning of Active Geographic Perception}

Human behavior is often purposeful, and the purpose is related to the subjective thoughts of the individual and the characteristics of the destination. For example, if a person who likes food but does not have significant digital hobbies goes to the digital shopping area, then his potential purpose should be to buy digital products,But traditional recommendation systems recommend gourmet products to users through their preference characteristics $^{[2]}$, this will lead to the generalization of recommended content to a certain extent, reducing the accuracy of recommendations ${ }^{[3]}$. In order to solve this problem, we need to combine user characteristics and situational features in the service recommendation.

In this paper, the user characteristics obtained through a large amount of data analysis and mining are called universal features, and the user characteristics (behavior preference) in a specific situation at a certain moment is called the context feature. Active geographic perception is an intelligent service recommendation technology that takes the user's preference characteristics from the universal level to the context level. Active geographic perception relies on the multi-dimensional geographic spatio-temporal data model. The destination features are indexed by time, and the spatial and attribute dimensions are collaboratively described. They are tagged at the natural, social and commercial levels, and their characteristics are abstracted to feature. The text reconstructs the destination context, and combines the user preference characteristics to infer the behavioral motives of the user at a specific place at a specific time, and finally calculates the user's situational characteristics. Active geo-aware technology can reduce the user's preference to the context level by reconstructing the situation, which can solve the problem of generalizing and solidifying push content in some cases, and improve the accuracy of intelligent services. High-precision positioning technology is the trigger basis for active geographic sensing, high-precision real-time positioning mainly solves location acquisition and initiative realization in active geo-sensing technology. Initiative is achieved based on changes in location, but since the user is moving, the position is changing in real time, not all position changes will trigger context reconstruction. In this paper, by combining the destination range, it is judged whether it is a valid position trigger by setting the position change value, thereby improving the service efficiency of the system.

\footnotetext{
* Jingwen Li - Lijw@glut.edu.cn
} 


\subsection{Active Geographic Perception Process}

Active geographic perception service flow is divided into two phases. The first stage is to acquire the longitude and latitude of mobile devices in real time according to positioning technology, and do inverse address resolution to the longitude and latitude to get the destination text, the second stage uses the destination as a key to retrieve the geographic feature information database, obtain the natural, social and commercial geographic feature information of the location, and infer the user's behavioral motives based on the user characteristics. The flow chart is as follows:

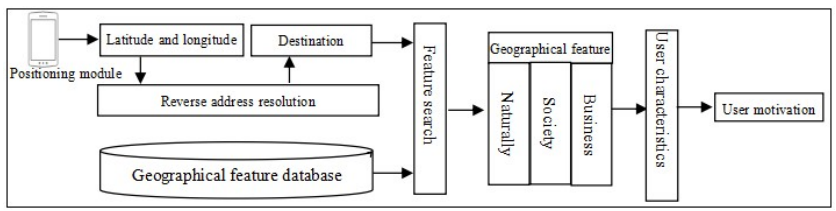

Figure 1 Active geographic awareness flow chart

The core content of active geographic awareness is to build a geographic feature database. This paper constructs a geographic feature database from three levels of business, nature and society.

\section{CONSTRUCTION OF ACTIVE GEOGRAPHICAL AWARENESS DATA MODEL}

\subsection{Feature classification}

This article divides geographic features into three categories: natural, social, and commercial. The specific classification is as follows:

(1) Natural characteristics

Natural characteristics are the characteristics of natural environment in a region. Because of the temporal nature of natural characteristics, they can be divided into dynamic and static categories according to their frequency of change.

\begin{tabular}{|c|c|c|}
\hline Dynamic & \multicolumn{2}{|c|}{ Static characteristics } \\
\hline $\begin{array}{l}\text { Character } \\
\text { Name }\end{array}$ & Parent class & Subclass \\
\hline weather & $\begin{array}{c}\text { Geographical } \\
\text { orientation } \\
\text { characteristics }\end{array}$ & $\begin{array}{l}\text { Location, traffic, } \\
\text { plates, altitude, etc. }\end{array}$ \\
\hline $\begin{array}{l}\text { temperature } \\
\text { humidity } \\
\text { wind } \\
\text { direction/speed } \\
\text { PM2.5 } \\
\text { PM10 } \\
\text { disastrous } \\
\text { weather } \\
\text { time }\end{array}$ & $\begin{array}{c}\text { River system } \\
\text { characteristics } \\
\text { Soil } \\
\text { characteristics } \\
\text { Climate and } \\
\text { environmental } \\
\text { characteristics } \\
\text { Topographical } \\
\text { features } \\
\text { Vegetation } \\
\text { characteristics }\end{array}$ & $\begin{array}{c}\text { Flow direction, water } \\
\text { flow, sediment } \\
\text { concentration, etc. } \\
\text { Fertile, barren, saline, } \\
\text { etc. } \\
\text { Marine climate, polar } \\
\text { iceland climate, etc. } \\
\text { Plains, mountains, } \\
\text { hills, etc. } \\
\text { Coniferous forest, } \\
\text { broad-leaved forest, } \\
\text { shrubs, etc. }\end{array}$ \\
\hline
\end{tabular}

Table 1 Natural Characteristic Table

(2) Social characteristics

The social characteristics reflect the national cultural characteristics of a region. According to the formation of characteristics, human beings participate in it, and they are divided into two categories: the direct function of human beings and the social characteristics indirectly formed by human activities.

\begin{tabular}{|c|c|}
\hline $\begin{array}{c}\text { Direct action characteristics } \\
\text { of human activities }\end{array}$ & $\begin{array}{c}\text { Indirect impact characteristics } \\
\text { of human activities }\end{array}$ \\
\hline National characteristics & Cultural characteristics \\
Demographic characteristics & Economic characteristics \\
Ethnographic characteristics & Dietary characteristics \\
Family characteristics & Architectural features \\
Other features & Religious characteristics \\
& Festive features \\
\hline
\end{tabular}

Table 2 Social characteristics table

\section{(3) Commercial characteristics}

The commercial characteristics are the regional commercial characteristics formed by regional business operations. The formation is related to the local natural resources, customs, policies and regulations. By analyzing the characteristics and contents of commercial operations, it is divided into the following categories.

\begin{tabular}{|c|c|}
\hline $\begin{array}{c}\text { Primary } \\
\text { classification }\end{array}$ & Secondary classification \\
\hline Diet & $\begin{array}{l}\text { Chinese restaurant }{ }^{[4]} \text { Western restaurant } \\
\text { special snacks, etc. }\end{array}$ \\
\hline Accommodation & $\begin{array}{c}\text { Star Hotel,Express Hotel Apartment Hotel } \\
\text { Youth Hostel Homestay, etc. }{ }^{[5]}\end{array}$ \\
\hline Shopping & $\begin{array}{l}\text { Shopping center, supermarket, } \\
\text { convenience store, shop, market, etc. }\end{array}$ \\
\hline $\begin{array}{l}\text { Domestic } \\
\text { services }\end{array}$ & $\begin{array}{l}\text { Communication,Business Office, Post } \\
\text { Office, Logistics, Company, etc. }\end{array}$ \\
\hline Beauty & Beauty, hair, manicure, body, etc. \\
\hline Tourist attraction & $\begin{array}{l}\text { Park zoo, botanical garden, amusement } \\
\text { park, museum aquarium, scenic area, etc. }\end{array}$ \\
\hline $\begin{array}{l}\text { Leisure and } \\
\text { entertainment }\end{array}$ & $\begin{array}{c}\text { Resort Farmhouse,Cinema KTV, Theatre } \\
\text { Ballroom, etc. }{ }^{[7]}\end{array}$ \\
\hline Work out & $\begin{array}{c}\text { Sports Venues,Extreme Sports,Fitness } \\
\text { Center, etc. }\end{array}$ \\
\hline $\begin{array}{l}\text { Education and } \\
\text { training }\end{array}$ & $\begin{array}{l}\text { Colleges and universities, middle schools, } \\
\text { primary schools, etc. }\end{array}$ \\
\hline Culture Media & $\begin{array}{c}\text { Press and Publication Radio and } \\
\text { Television, Art Group, etc. }\end{array}$ \\
\hline Medical service & General hospital, specialist hospital, etc. \\
\hline Car services & Car Sales, Car Repair, Car Beauty, etc. ${ }^{[8]}$ \\
\hline Financial & Bank, ATM, etc. \\
\hline Real estate & Office building residential area, etc. \\
\hline Corporate & $\begin{array}{l}\text { Company park agriculture, forestry and } \\
\text { horticulture factory mine, etc. }\end{array}$ \\
\hline $\begin{array}{l}\text { Government } \\
\text { agency }\end{array}$ & $\begin{array}{l}\text { Central institutions, governments at all } \\
\text { levels, administrative units, etc. }\end{array}$ \\
\hline
\end{tabular}

Table 3 Business Characteristics Table

\subsection{Feature extraction}

Natural and commercial features are characterized by stability and wide range. These features are obtained through a large Q\&A platform. Commercial data ranges are relatively small 
(blocks), and commercial data has a determined latitude and longitude, so this type of data is obtained from POI data ${ }^{[9]}$.

(1) Natural and social feature extraction

Dynamic features are acquired in real time through an open API interface, and static and social features are implemented using network data capture and manual intervention auditing. The network crawling features mainly include four steps: feature text acquisition, Chinese word segmentation, feature extraction and manual review. The flow chart of feature extraction is as follows:

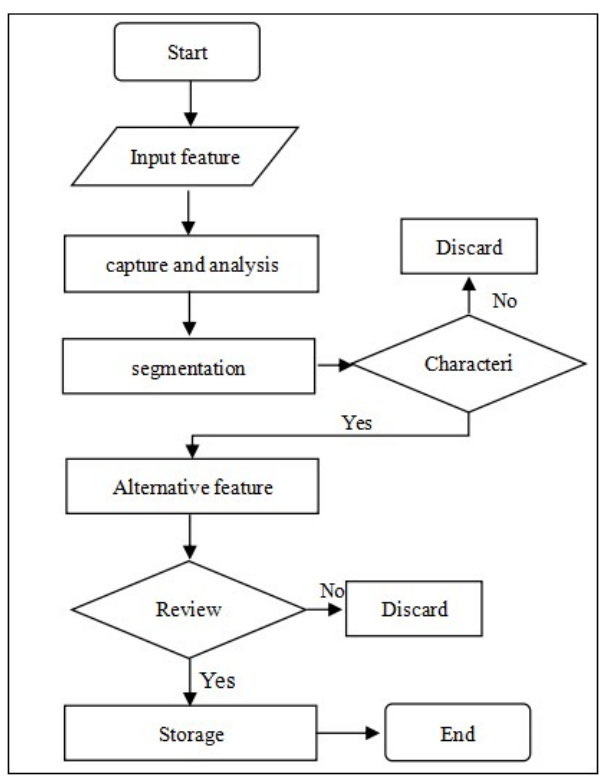

Figure 2 Feature extraction process

(2) Commercial feature extraction

The commercial feature is calculated based on the POI data, and the calculation is based on the latitude and longitude of the POI. Calculate the proportion of different types of POIs in a specific area based on latitude and longitude,this ratio is the commercial characteristics of the area.

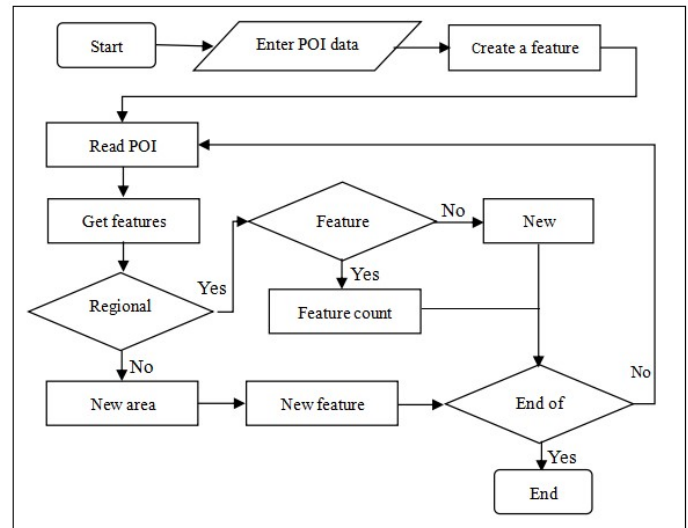

Figure 3 Business feature extraction process

The commercial feature weight calculation is based on the ratio of a certain feature to the total number of feature categories in the region, Calculated as follows ${ }^{[10]}$ :

$$
P_{i}=\operatorname{tags}_{i} / \sum_{j=0}^{n} \operatorname{tags}_{j}
$$

\subsection{Construction of multidimensional geographic space- time feature model}

The Bson (Binary Serialized Document Format) format is selected as the format basis of the geographic feature information model. The complete structure of the model is as follows:

\begin{tabular}{|c|c|c|c|c|}
\hline \multicolumn{5}{|c|}{ Bson } \\
\hline \multicolumn{5}{|c|}{ ObjID: Object unique identifier } \\
\hline \multicolumn{5}{|c|}{ Basic Information : } \\
\hline Name & & xyz & & $\ldots$ \\
\hline \multicolumn{5}{|c|}{ Characteristic information: } \\
\hline natura & & society & & business \\
\hline -feature 1 & 1 & \begin{tabular}{|l|}
-feature 1 \\
\end{tabular} & 1 & \begin{tabular}{|l|l|}
-feature 1 & 0.8 \\
\end{tabular} \\
\hline -feature 2 & 1 & -feature2 & 1 & -feature 20.7 \\
\hline -feature 3 & 1 & -feature 3 & 1 & -feature 30.6 \\
\hline
\end{tabular}

Figure 4 Geographic feature information model structure

Since the geographic feature information model is based on the Bson format and uses MongoDB storage, it can be directly manipulated using the methods provided by the MongoDB database.

\section{USER BEHAVIOR MOTIVATION INFERENCE METHOD BASED ON ACTIVE GEOGRAPHIC PERCEPTION}

The ultimate goal of active geographic awareness is to infer the user's behavioral motivation by reconstructing the situation, the process is: Firstly, the geographical feature information of the user's location is obtained, which includes the geographic feature tag and the feature weight. Secondly, the user's preference information is retrieved. Finally, based on the geographic feature and user preference, the association weight is used to obtain the feature weight of the combination. According to the weight, the user behavior motivation is inferred, and the user does not push the more accurate and personalized service. User motivation inference flow chart is as follows:

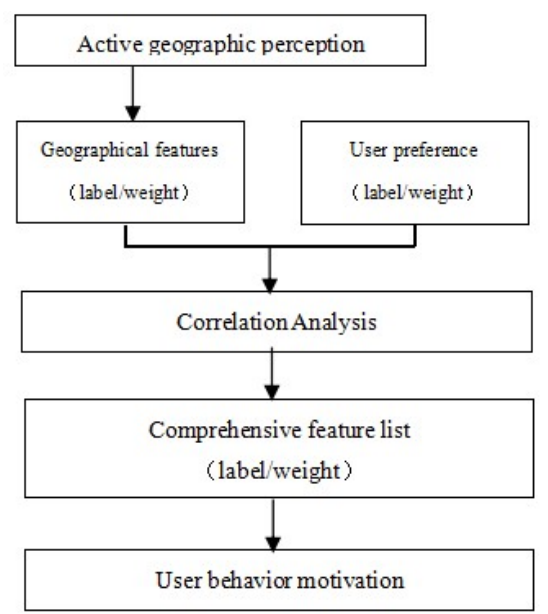

Figure 5 User motivation inference process

The most central part of inferring user motivation is the association analysis of geographic features and user preferences, The process of its analysis is as follows: 
(1) Build geographic feature tags and weight distributions, Recorded as L:

$$
L=\left\{\left\{l l_{1}, l w_{1}\right\},\left\{l l_{2}, l w_{2}\right\},\left\{l l_{3}, l w_{3}\right\} \ldots,\left\{l l_{n}, l w_{n}\right\}\right\}
$$

(2) Construct user preference feature tags and weight distribution, Recorded as $\mathrm{P}$ :

$$
P=\left\{\left\{p l_{1}, p w_{1}\right\},\left\{p l_{2}, p w_{2}\right\},\left\{p l_{3}, p w_{3}\right\} \ldots,\left\{p l_{m}, p w_{m}\right\}\right\}
$$

Correlate analysis of $\mathrm{L}$ and $\mathrm{P}$ to obtain comprehensive features

Z:

$$
Z=\left\{\left\{z l_{1}, z w_{1}\right\},\left\{z l_{2}, p w_{2}\right\},\left\{z l_{3}, z w_{3}\right\} \ldots,\left\{z l_{k}, z w_{k}\right\}\right\}
$$

$k=m \times n \quad z l_{i}$ represents the i-th comprehensive feature, $z w_{i}$ represents the weight of the i-th composite feature, $z w_{i}$ calculation method is as follows:

$$
z w_{i}=\left(l w_{i} \times p w_{i}\right) / \sum_{i=1}^{m \times n}\left(l w_{i} \times p w_{i}\right)
$$

\section{IN CONCLUSION}

This paper mainly studies the method of user behavior motivation inference based on active geographic perception, Firstly, the active geographic perception is defined and the process of inferring user behavior motivation is introduced. Then the process of data classification, acquisition, processing and modeling of geographic feature modeling is studied in detail. Finally, the intelligent geographic sensing technology based intelligence is designed. By considering the situation, it provides a new idea for intelligent services to improve accuracy and personalization.

\section{ACKNOWLEDGEMENTS}

This paper is supported by the National Natural Science Foundation of China(No.41961063), and Innovation Project of Ministry of Culture and Tourism of the People's Republic of China(No.2019-011).

\section{REFERENCES}

Xi Chang. Research on Archives Service in the Construction of Smart City [D]. Heilongjiang University,2018.

Zhang Wenying. Research of a rule-based personalized location-based recommendation system in mobile application [D]. Harbin Institute of Technology,2013.

Li Mo, Liang Yongquan, Zhao Jianli, Li Yujun. Research of Hybrid recommendation system model for internet video [J]. Computer engineering and design,2013,34(12):4379-4383.

Lin Xingjin. The Design and Implementation of Wireless Meal Ordering System Based on the Platform of Android [D]. Beijing Jiaotong University,2013.

Xiao Honglei,Guo Jianbing,Ouyang Zhaoyan.the current situation and countermeasure for the development of kunming's hotel-style-serviced apartment [J]. Journal of Qujing Normal University,2010,29(04):63-67.

Zhuang Chutian. A Spatial Analysis of Public Bicycle System Based on GIS and Web Crawler Technology [D]. Soochow University,2017.
Deng Lifan,Xie Yonghong,Huang Dingwei. Bicycle-sharing Facility Planning Base On Riding Spatio-temporal Data [J]. Planner,2017,33(10):82-88.

Yuan Jianrong. Automotive aftermarker system structure and operation mode studying of Chang-an group [D]. Chongqing University,2007.

$\mathrm{Lu}$ Yuanyuan. Research of Ontology-based Logistics Information System Integration Method [D]. Shandong University of Science and Technology,2010.

Qin Fei, Yang Yan. Research on Document Classification Algorithm Based on Semi-Supervised Learning [J]. Computer Engineering and Science,2010,32(09):127-129. 